\title{
Oficinas para exercício do texto: o papel da residência pedagógica na formação do professor de língua portuguesa
}

\author{
Myllena Araujo \\ Universidade Federal da Paraíba \\ myllenaaraujonascimento@gmail.com \\ https://orcid.org/0000-0001-7480-9265 \\ José Wellisten Abreu de Souza \\ Universidade Federal da Paraíba \\ josewellisten@hotmail.com \\ https://orcid.org/0000-0002-4232-4551 \\ Antônio Barboza da Silva \\ Universidade Federal da Paraíba \\ profantonnio.j@gmail.com \\ https://orcid.org/0000-0001-5805-4018
}

RESUMO: Objetiva-se uma análise sobre a prática desenvolvida ao longo da Oficina de Argumentação, experiência relativa ao contexto da Residência Pedagógica - Núcleo Língua Portuguesa. Para isso, avalia-se o desempenho e a progressão da escrita de duas das participantes mais assíduas da oficina, que desenvolveu a preparação para a produção do tipo dissertativo-argumentativo, exigido na redação do Exame Nacional do Ensino Médio (Enem). Metodologicamente, apresenta-se relato de experiência aliado a uma análise qualitativa do desempenho das estudantes. Nosso corpus é composto de oito trechos extraídos das produções semanais da oficina e nossa análise pauta-se nos parâmetros preconizados pelas competências II e III do Enem. Do ponto de vista teórico, considera-se Kleiman (2006), Moita Lopes (2006) e Bunzen (2006). Em síntese, a formação inicial e continuada de futuros professores está na essência do que prevê o programa Residência Pedagógica, desenvolvendo nos residentes a observação sobre sua própria ação-docente, a qual é revelada como meio reflexivo.

PALAVRAS-CHAVE: Residência pedagógica. Língua portuguesa. Enem.

\section{WORKSHOPS FOR EXERCISING THE TEXT: THE ROLE OF THE PEDAGOGICAL RESIDENCE IN THE TRAINING OF THE PORTUGUESE LANGUAGE TEACHER}

ABSTRACT: We analyze the pedagogical practice developed during the Argumentation Workshop, an experience related to the context of the Pedagogical Residence - Portuguese Language Center. For that, the progression of writing component of two of the most assiduous participants of the workshop are evaluated, which embodies the preparation for the production of the dissertative-argumentative type, used in the essay of the Exame Nacional do Ensino Médio (Enem). Methodologically, an experience report combined with a qualitative analysis of the student's performance is presented. Our corpus is composed of eight excerpts extracted from the weekly productions of the workshop and our analysis covers the parameters recommended by competences II and III of Enem. From a theoretical perspective, Kleiman (2006), Moita Lopes (2006) and Bunzen (2006) are considered. Hence, the overall training of future teachers is the essence of what the Pedagogical Residency program provides, developing in the residents the observation about their own teaching action which it is revealed as a reflexive mean.

KEYWORDS: Pedagogical residence. Portuguese language. Enem. 


\section{INTRODUÇÃO}

A Residência Pedagógica (RP) é um programa planejado pela Coordenação de Aperfeiçoamento de Pessoal de Nível Superior (CAPES) que integra a Política Nacional de Formação de Professores. Nesse contexto, o Governo Federal, através da Portaria ${ }^{\circ}$ 38 , de 28 de fevereiro de $2018^{1}$, institui a RP com a premissa fundamental de, em linhas gerais, "(...) induzir o aperfeiçoamento da formação prática nos cursos de licenciatura, promovendo a imersão do licenciando na escola de educação básica (...)" (BRASIL, 2018, p. 1).

Nesse sentido, pode-se concluir que o objetivo da RP é melhorar o ensino público por meio da profissionalização dos licenciandos, promovendo uma vivência de imersão no ambiente escolar orientada por docentes universitários de suas respectivas áreas, além dos preceptores (termo utilizado no contexto do programa Residência Pedagógica para classificar os professores da Educação Básica inscritos no programa e que atuam supervisionando os residentes na escola-campo) de cada escola participante.

O núcleo de Letras Português da Universidade Federal da Paraíba (UFPB), Campus I, reuniu, em 2019, um grupo composto por trinta e um alunos, dois professores coordenadores e três preceptoras ${ }^{2}$. Dois participantes do presente artigo cumpriram suas atividades no Instituto Federal da Paraíba (IFPB), campus João Pessoa, onde, acompanhados por uma preceptora, ministraram aulas de Língua Portuguesa em turmas do Ensino Médio (EM). Na ocasião, foi oferecido para os alunos matriculados no EM da instituição um curso de produção textual que, inicialmente, se propôs a ser uma Oficina de Argumentação, perdendo depois esta característica devido à longa duração e à frequência dos encontros ocorridos durante o ano de 2019. Por conta disso, assumiu características semelhantes às de um curso de produção de textos, com ênfase na preparação para o Enem ${ }^{3}$. Desse modo, atendeu-se ao seguinte objetivo da RP, conforme Portaria $n^{\circ}$ 38/02/2018:

I. Aperfeiçoar a formação dos discentes dos cursos de licenciatura, por meio do desenvolvimento de projetos que fortaleçam o campo da prática e que conduzam o licenciando a exercitar de forma ativa a relação entre teoria e prática profissional docente, utilizando coleta de dados e diagnóstico sobre o ensino e a aprendizagem escolar, entre outras didáticas e metodologias (BRASIL, 2018, p. 1).

Considerando a pertinência de um debate sobre algumas das práticas pedagógicas articuladas pelos residentes ao longo da execução deste programa, este artigo tem como objetivo realizar uma análise sobre a prática desenvolvida ao longo da Oficina de Argumen-

\footnotetext{
1 Portaria $\mathrm{n}^{\circ} 38$ disponível em: <https://www.gov.br/capes/pt-br/centrais-de-conteudo/28022018-portaria-n-38-institui-rp-pdf/view>, acesso em 29 set. 2020.

2 A esse respeito, registramos a nossa gratidão à prof ${ }^{a}$. Dra. Mônica Mano Trindade Ferraz, responsável pela Coordenação do núcleo de Residência Pedagógica de Letras na Universidade Federal da Paraíba, e à profa. Ma. Alessandra Gomes Coutinho Ferreira, preceptora de Língua Portuguesa no Instituto Federal da Paraíba, campus João Pessoa.

3 A escolha pelo foco do trabalho dos residentes com o gênero dissertativo-argumentativo, ao longo da Oficina de Argumentação, se deu em virtude de este ser o único gênero textual cobrado pela prova de redação do Enem no momento, principal exame para a entrada nas universidades públicas brasileiras.
} 
tação e ainda avaliar o desempenho e a progressão da escrita de dois dos mais assíduos participantes deste curso ministrado em 2019 no IFPB.

À luz da BNCC, por exemplo, percebemos uma forte preocupação com práticas pedagógicas que visam a melhoria da proficiência escrita de alunos, principalmente aqueles que estão matriculados nos anos de nível médio, em sua maioria, candidatos aos certames vestibulares e/ou Enem. Na caracterização da área de Língua Portuguesa no contexto do Ensino Médio, o documento assevera ser necessário uma

\begin{abstract}
atenção maior nas habilidades envolvidas na produção de textos multissemióticos mais analíticos, críticos, propositivos e criativos, abarcando sínteses mais complexas, produzidos em contextos que suponham apuração de fatos, curadoria de informação, levantamentos e pesquisas e que possam ser vinculados de forma significativa aos contextos de estudo/construção de conhecimentos em diferentes áreas, a experiências estéticas e produções da cultura digital e à discussão e proposição de ações e projetos de relevância pessoal e para a comunidade (BRASIL, 2017, p. 492).
\end{abstract}

No caso das ações desenvolvidas na RP, nota-se que a prática da Oficina de Argumentação, desenvolvida ao longo de 2019, possibilitou aos residentes experienciar alguma vivência com relação às escolhas de suas propostas didáticas.

Do ponto de vista metodológico, a partir de uma amostra dos dados acumulados durante o curso de argumentação citado, constrói-se a análise qualitativa do desempenho de duas das participantes mais assíduas na oficina frente às propostas de produção de textos do gênero dissertativo-argumentativo. O recorte da análise está definido com base nos parâmetros preconizados pelas competências II e III do Exame Nacional do Ensino Médio (Enem), sendo nosso corpus composto por oito trechos das redações selecionadas.

Dentre as cinco competências de análise do tipo dissertativo-argumentativo do Enem, a escolha pelas competências II e III se deu em virtude de estas duas serem responsáveis pela avaliação da autoria do aluno, sendo a II caracterizada pela forma como o participante se apropria da proposta de redação, bem como demonstra conhecimento sobre a estrutura do gênero. A competência III, por sua vez, avalia a construção de sentido do texto, a partir de seleção dos argumentos mais adequados em defesa de um ponto de vista ${ }^{4}$ (BRASIL, 2019).

A partir das escolhas ora mencionadas, a estruturação deste artigo seguirá um itinerário que se inicia com uma exposição sobre a fundamentação teórica necessária para a análise das competências II e III do Enem, aspecto relevante ao debate que se pretende fazer no presente texto. Além disso, apresentam-se, ao longo da análise, alguns trechos de redações produzidas por discentes da escola-campo, cujos resultados contribuirão para a composição de um quadro crítico-reflexivo acerca da produtividade da oficina ministrada, no que diz respeito ao desempenho progressivo dos alunos. Como efeito da avaliação da produtividade da oficina, realiza-se, também, uma avaliação quanto à pertinência da

\footnotetext{
4 As informações acerca das competências II e III foram retiradas dos Módulos 4 e 5 das apostilas de capacitação dos corretores de redação do Enem da edição de 2019. O material foi disponibilizado pelo INEP, em maio de 2020, através do site: http://portal.inep.gov.br/web/guest/ enem-outros-documentos.
} 
RP enquanto espaço reservado à formação docente, além da contribuição da oficina para melhoria da escrita dos alunos no que concerne ao gênero dissertativo-argumentativo. Por último, indicam-se nossas considerações finais e as referências utilizadas para a elaboração deste artigo.

\section{O ENSINO DA PRODUÇÃO DE TEXTO NO ENSINO MÉDIO: A CENTRALIDADE NO TRABALHO COM OS GÊNEROS TEXTUAIS}

Desde o final do século XVIII até meados do século XX, houve uma relevância maior, nas aulas de Língua Portuguesa, para o ensino centrado nas regras gramaticais e na leitura em detrimento do ensino da escrita 5 . Segundo Bunzen (2006, p. 144),"foi apenas durante as décadas de 1960 e 1970 que começamos a perceber algumas novidades em relação ao ensino da então chamada redação escolar"6.

A incorporação da prática vinculada a esta terminologia trouxe consigo a visão da língua como código, sendo uma influência "da teoria matemática da comunicação, mais especificamente, dos trabalhos de engenharia de telecomunicação, que descreviam os processos físicos de transmissão de informação" (CUNHA, 2004, p. 27). Esta visão da língua, associada também a uma das doutrinas vinculadas ao estruturalismo saussureano ${ }^{7}$, se perpetuou e obteve intensa presença nas aulas de Língua Portuguesa até o final da década de 1970.

A introdução da noção de ensino de língua baseada nos estudos linguísticos, por parte dos principais documentos educacionais brasileiros ${ }^{8}$, trouxe avanços significativos para a realidade escolar brasileira a partir da década de 1980, momento em que alguns paradigmas eram (re)discutidos e superados em virtude da ascensão da Linguística Textual. Dentre algumas mudanças concretizadas, houve a adoção de uma perspectiva que enxergava o texto, a partir de então, como uma unidade de ensino. Os gêneros, nesse contexto, passam a consistir em objetos de ensino (BUNZEN, 2006).

Ao tratar sobre a perspectiva de Análise Linguística (AL), Geraldi (1984[2006]) afirma que "a única coisa que [1he] parece essencial na prática de análise linguística é a substituição do trabalho com metalinguagem pelo trabalho produtivo de correção e auto-correção de textos produzidos pelos próprios alunos" (2006, p. 68) [negrito do original]. Neste artigo, o autor está preocupado em apresentar sugestões de atividades voltadas para as práticas de leitura e produção de texto, para tanto ele considera a $\mathrm{AL}$ como um dos eixos (associada aos anteriores) básicos do ensino de língua materna. Essas discussões, inclusive, vão influenciar a concepção de gêneros textuais e o ensino de Língua Portuguesa (LP), centrado no texto como o conhecemos hoje, processo, inclusive, promovido pelos Parâmetros Curriculares Nacionais (PCNs).

\footnotetext{
5 Para mais detalhes, aconselhamos a leitura de Bunzen (2006).

6 Apesar dessas novidades, Rojo e Cordeiro (2004, p. 8) afirmam que o texto "era tomado como objeto de uso, mas não de ensino-aprendizagem".

7 Vale mencionar, sobre o assunto, que Bakhtin/Volochínov (2014) já criticava a tendência a um objetivismo abstrato que se formatava em função da noção de que a língua consistia numa entidade imutável.

8 Como exemplos, podemos citar os Parâmetros Curriculares Nacionais (PCN+, BRASIL, 2002), Base Nacional Comum Curricular (BNCC, 2018), dentre outros.
} 
Ainda no sentido da tendência preconizada a partir da década de 1980, de acordo com as diretrizes dos Parâmetros Curriculares Nacionais ( $\mathrm{PCN}+$ ), "quando se pensa no trabalho com textos, outro conceito indissociável diz respeito aos gêneros em que eles se materializam, tomando-se como pilares seus aspectos temáticos, composicionais e estilísticos" (BRASIL, 2002, p. 77). Seguindo essa premissa, o ensino de língua tendo como foco os gêneros textuais abarca a visão sociointeracionista, que pensa o estudo sócio-histórico dos gêneros como uma maneira de compreender o funcionamento social da língua9.

Apesar de todo o progresso oriundo da implantação do ensino dos mais diversos gêneros textuais escritos e orais nas aulas de Língua Portuguesa, percebe-se, na contemporaneidade, a continuidade da prática quase unificada do ensino de apenas determinados gêneros textuais escritos. Ao considerar o contexto do Ensino Médio brasileiro, geralmente, vê-se sendo determinados esses gêneros pelos principais vestibulares do país, o que não reproduz os preceitos postos nos documentos educacionais. Conforme Bunzen (2006),

É decisão política escolher se teremos como objetivo principal e final a formação de alunos no EM que produzem na escola (e nos cursinhos) apenas as propostas de redações do vestibular das principais universidades de cada estado ou investiremos em um processo de ensino-aprendizagem que leve em consideração a prática social de textos em outras esferas de comunicação (BUNZEN, 2006, p. 151).

Ou seja, nota-se que há, atualmente, uma distorção da produção textual enquanto prática comunicativa e uma distância entre a vivência escolar e a realidade social dos alunos, visto que, ao escrever quase que majoritariamente gêneros designados por provas de vestibulares, há uma dissociação entre a adoção da concepção de prática social ${ }^{10} \mathrm{e} o$ ensino de produção textual. Ao contrário disso, deve-se compreender o processo ensino-aprendizagem do texto como "(...) a prática social que viabiliza a exploração do gênero, e não o contrário" (KLEIMAN, 2006, p. 33). Em conformidade com essa perspectiva, Geraldi (2006) observa que

$\mathrm{Na}$ prática escolar, institui-se uma atividade linguística artificial: assumem-se papéis de locutor/interlocutor durante o processo, mas não se é locutor/interlocutor efetivamente. Essa artificialidade torna a relação intersubjetiva ineficaz, porque a simula (GERALDI, 2006, p. 89).

À luz das reflexões fornecidas em Kleiman (2006) e Geraldi (2006), portanto, observa-se que a adoção de gêneros escolares torna o exercício de aquisição da proficiência escrita uma experiência que além de não consistir enquanto prática comunicativa, não estabelece de maneira concreta uma relação locutor/interlocutor conforme aquela experimentada na realidade objetiva em que escritas dos mais diversos gêneros costumam se consolidar.

9 Ver Marcuschi (2008).

10 Para mais detalhes sobre o conceito de prática social, ver Kleiman (2006). 
Para além do descompasso entre as concepções teóricas atualmente imperantes e as práticas sociais concretas, temos, segundo Moita Lopes (2006), um contexto de escassa visibilidade para a discussão de uma teoria comprometida com a realidade sociopolítica concreta do Brasil. Em resposta a isso, temos o surgimento de uma Linguística Aplicada (LA) de caráter mais intempestivo e assumidamente comprometida com pautas que visam englobar aqueles usuários que se pressupõem ignorados do processo de formulação dos corpora da Linguística disciplinar.

Nesse sentido, Moita Lopes (2006, p. 26) afirma que "não surpreende que essa visão da LA como Indisciplina, além de causar desconforto, represente muitas vezes uma ameaça para aqueles que vivem dentro dos limites disciplinares, com verdades únicas, transparentes e imutáveis".

Assumindo a existência de um desafio que necessita ter suas demandas atendidas, assinala-se, dentro da perspectiva defendida por Moita Lopes (2006), a urgência por uma produção de conhecimento que ofereça maior protagonismo para as vozes do sul, isto é, que inclua na formulação de seu(s) corpus e nas escolhas de suas fundamentações teóricas as pessoas que historicamente vivem à margem da sociedade (negros, indígenas, homossexuais etc.).

Em outras palavras, ao assumirmos a concepção de uma LA ancorada na prática social (KLEIMAN, 2006, p. 26), alinhada ainda à percepção de que o gênero é o próprio objeto de ensino (MARCUSCHI, 2008, p. 51), e observando as condições impostas pela realidade objetiva da sociedade (consequentemente, considerando a condição dos usuários da língua), este trabalho busca viabilizar também uma pesquisa mais sensível às preocupações sociais que impõem-se no atual contexto do ensino. Vale ressaltar que a reinvenção dos constructos teóricos dominantes, necessidade já apontada por Moita Lopes (2006), constitui uma tendência que, adotada em associação com as demais, deve contribuir para a resolução de demandas dos próprios estudantes, dentre elas a aquisição da proficiência escrita exigida pelos principais vestibulares do país como requisito para $o$ ingresso na universidade.

Apesar de o Brasil possuir vários vestibulares estaduais importantes ${ }^{11}$, atualmente, o Exame Nacional do Ensino Médio (Enem) ${ }^{12}$ é o principal meio de entrada para as universidades públicas brasileiras, além de ser aceito como ingresso em instituições estrangeiras. A prova foi criada em 1998 com o intuito, inicialmente, de avaliar a qualidade da educação brasileira e desde 2009 tem sido usada, também, para o acesso ao ensino superior.

A prova de Redação exige do discente "a produção de um texto em prosa, do tipo dissertativo-argumentativo, sobre um tema de ordem social, científica, cultural ou política" (BRASIL, 2019, p. 5). Além disso, os alunos são avaliados pelos corretores mediante

11 Como exemplos podemos citar a Fundação Universitária para o Vestibular (Fuvest), responsável pelo vestibular da Universidade de São Paulo (USP), a Comissão Permanente para os Vestibulares (Comvest), responsável pelo vestibular da Universidade Estadual de Campinas (UNICAMP), dentre outros.

12 Segundo a Matriz de Referência do Enem, a prova é composta por quatro áreas do conhecimento: Ciências da Natureza e suas Tecnologias, Ciências Humanas e suas Tecnologias, Linguagens, Códigos e suas Tecnologias e Matemática e suas Tecnologias, além da prova de Redação. 
cinco competências. Dentre estas, nosso foco será na análise das competências II e III, como veremos na próxima seção.

\section{VAMOS COLOCAR A MÃO NA MASSA? O TRABALHO COM A PRODUÇÃO DE TEXTO NO CONTEXTO DA OFICINA DE ARGUMENTAÇÃO}

Ao longo do ano de 2019, durante a execução da Oficina de Argumentação, foram ministradas aulas sobre as características estruturais e linguísticas que norteiam o tipo dissertativo-argumentativo, além disso, foram promovidos debates semanais sobre temas socioculturais divergentes, tal como preconizam as diretrizes do Enem. A partir do resultado dessas aulas, os discentes participantes da oficina escreveram redações semanalmente, as quais eram corrigidas pelos residentes, dois dos autores deste artigo. As correções objetivavam acompanhar o desempenho dos alunos durante as aulas, tendo como foco tanto a análise, por parte dos residentes, e o feedback, aos discentes, das competências textuais em que haviam progressões em relação às produções textuais anteriores, quanto das competências textuais em que eram verificadas maiores dificuldades.

Com o intuito de aperfeiçoar cada vez mais os textos dos alunos, os residentes sugeriam aos discentes a reescrita das produções que não recebiam nota máxima, sendo feita uma nova correção e comparação da evolução do texto em relação ao anterior. Apesar do incentivo à reescrita ao longo de toda a oficina, não houve uma adesão constante desta prática por toda a turma. Contudo, os textos selecionados para esta análise são de duas das discentes que mais praticaram a reescrita.

À medida que as correções ocorriam, notas eram atribuídas e as redações eram arquivadas em uma planilha que era atualizada semanalmente com as informações sobre a presença e o desempenho de cada aluno ao longo da oficina. Além disso, para este trabalho, analisamos a progressão de duas alunas, com base nas evoluções qualitativas das produções textuais. Nosso intuito foi analisar três redações de cada discente feitas ao longo de 2019, com foco nas progressões das competências II e III do gênero dissertativo-argumentativo.

A prática pedagógica de um docente de língua materna é diretamente influenciada por sua concepção de linguagem, pois, de acordo com Travaglia (2002, p. 21), "a concepção de linguagem é tão importante quanto à postura que se tem relativamente à educação". O aprendizado da produção textual de diferentes gêneros discursivos é uma das principais habilidades desenvolvidas no ensino de língua portuguesa ao longo do Ensino Básico, pois partindo da concepção da competência comunicativa da língua ${ }^{13}$, o aluno deve finalizar o Ensino Médio possuindo habilidades linguísticas suficientes para dominar o uso dos mais diversos gêneros textuais escritos ou orais que circunscrevem o cotidiano social.

Os documentos educacionais brasileiros que norteiam as práticas pedagógicas, como os Parâmetros Curriculares Nacionais do Ensino Médio (PCNEM), focalizam o texto no trabalho da língua no Ensino Médio. Segundo o documento "(...) O ensino e a

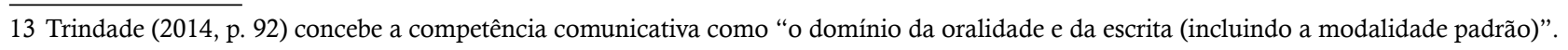


aprendizagem de uma língua não podem abrir mão dos textos, pois estes, ao revelarem usos da língua e levarem a reflexões, contribuem para a criação de competências e habilidades específicas" (BRASIL, 2000, p. 55).

A incorporação do Exame Nacional do Ensino Médio (Enem) como o principal meio de entrada para as universidades públicas brasileiras, desde 2009, gerou um efeito retroativo nas aulas do ensino básico brasileiro, principalmente no Ensino Médio, período de maior preocupação com o vestibular por parte dos discentes e dos docentes. Uma das mais significativas mudanças na prática escolar das aulas de língua portuguesa, desde então, foi a centralidade do ensino do tipo dissertativo-argumentativo nas aulas de redação.

A importância concedida a este tipo na atualidade foi constatada pelos residentes, ao longo do nosso cotidiano no IFPB em 2019, pois houve uma adesão maciça dos alunos do ensino médio, principalmente do terceiro ano, na Oficina de Argumentação, diferentemente da nossa proposta de uma Oficina de Poesia neste mesmo período a esse mesmo grupo de estudantes, em que não houve o interesse de participação dos alunos.

Durante todo o período da Oficina de Argumentação, foram ministradas quase trinta aulas sobre as diferentes competências que são exigidas na escrita da redação dissertativo-argumentativa, desde conteúdos gramaticais como o uso da crase, concordância verbal e nominal, acentuação, dentre outros, até assuntos interdisciplinares, como a discussão de temas socioculturais a partir de diferentes abordagens (filosófica, literária, cinematográfica etc.), sendo este um conhecimento necessário para a construção de uma redação dissertativo-argumentativa dentro dos parâmetros requeridos no exame.

Apesar desse leque extenso de conteúdos, optou-se, neste artigo, pelo recorte do relato da prática pedagógica referente ao ensino das competências e habilidades exigidas nas competências II e III da redação do Enem ${ }^{14}$, bem como a análise da evolução qualitativa de duas discentes nestas competências ao longo da oficina ${ }^{15}$.

Vale mencionar que das cinco competências do Enem, as competências II e III são as que mais reúnem características relativas à capacidade de o aluno demonstrar a sua autoria, sendo a originalidade do texto um aspecto valorizado nessas competências. Para exemplificar, vale recuperar o que consta na cartilha do participante acerca disso: o candidato atinge 200 pontos na competência 2 quando "Desenvolve o tema por meio de argumentação consistente, a partir de um repertório sociocultural produtivo, e apresenta excelente domínio do texto dissertativo-argumentativo" (BRASIL, 2020, p. 20) e o candidato atinge 200 pontos na competência 3 quando "Apresenta informações, fatos e opiniões relacionados ao tema proposto, de forma consistente e organizada, configurando autoria, em defesa de um ponto de vista" (BRASIL, 2020, p. 22).

Com base no exposto, apoiando-nos no que sugere Mata (2017), vê-se que o que se espera do candidato para a atribuição da pontuação máxima em cada competência é que

14 Faz-se importante mencionar que o texto dissertativo-argumentativo presente no Enem possui cinco critérios de correção.

15 Para este artigo, houve a escolha metodológica de analisar trechos de redações de duas discentes participantes da oficina. No entanto, durante o período da oficina, houve a correção integral de todas as redações produzidas pelos alunos. 
tanto se demonstre um uso/conhecimento produtivo da forma (das normas linguísticas, da coesão e da coerência) como também que se demonstre amplo domínio de conteúdo, em que pese o saber desenvolver seu texto por meio da utilização adequada de conhecimentos de mundo, conhecimentos enciclopédicos etc., o que deve ser atrelado ao modo estratégico como o produtor do texto seleciona as informações, organiza as suas ideias, se torna autor (original) de seu próprio texto.

A despeito da rigidez estrutural do tipo dissertativo-argumentativo, o que, muitas vezes, inibe a capacidade criativa do aluno, procurou-se, durante as aulas no papel de residentes, estimular a originalidade/autoria dos discentes enquanto sujeitos produtores de um determinado objeto sociocomunicativo, e não apenas como pré-vestibulandos produzindo textos maquinalmente com o único intuito de alcançar determinada nota em uma prova.

Nas primeiras aulas da Oficina de Argumentação, procuramos trabalhar conteúdos referentes aos aspectos estruturais do tipo dissertativo-argumentativo, assuntos gramaticais que os alunos relataram mais dificuldade na hora da escrita, como a pontuação, e discutimos temas com problemáticas pertinentes na realidade brasileira contemporânea. Uma das primeiras temáticas que abordamos em aula foi "A questão do analfabetismo funcional no Brasil", ministrada no mês de abril. Dentre as redações produzidas pelos discentes, selecionou-se analisar a evolução no desempenho das competências II e III a partir de trechos de três textos de duas alunas ${ }^{16}$. Eis a introdução da primeira redação do aluno 1:

Quadro 1: Trecho 1, Aluno 1, Texto 1.

Funcionando como a primeira lei de Newton, a lei da inércia que um corpo tende a permanecer no seu
movimento até que uma força suficiente atua sobre ele mudando o de percurso. O analfabetismo funcional
é um problema que persiste na sociedade brasileira. Com isso, ao invés de funcionar como uma força
suficiente, capaz de mudar o percurso do problema da persistência para a extinção, a combinação dos
fatores exclusão da escola e baixa qualidade de ensino acaba por contribuir com a persistência do problema.

Dados da Oficina, 2019.

Neste trecho, há a presença de um repertório sociocultural legitimado, através da citação da primeira lei de Newton, e a explicitação da tese, ao final do parágrafo, que sugere duas problemáticas as quais serão abordadas ao longo do desenvolvimento. Apesar desses pontos positivos nesta introdução, não há uma relação argumentativa produtiva entre o repertório sociocultural e a problemática na sociedade brasileira atual, o que compromete a aparição do autor neste parágrafo o que, segundo Foucault (2009), é parte do tecido discursivo. A avaliação dos aspectos autorais em redações escolares, como o tipo dissertativo-argumentativo, busca captar a marca pessoal de quem produz esse discurso, autor este que não deve ser confundido, neste caso, com um sujeito empírico, mas sim com um sujeito que pode ser desvelado na própria produção textual, como aponta Mata (2017). Assim, há nesta introdução muito mais a reprodução de informações do

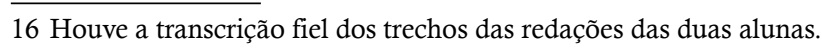


repertório que a interpretação destes em relação ao tema, o que configura a defesa de um ponto de vista, mas não alcança o patamar de uma autoria, conforme o Material de Leitura da competência III disponibilizado pelo Inep (BRASIL, 2019).

O desenvolvimento da redação dissertativo-argumentativa é o espaço em que há, geralmente, a maior quantidade de linhas e onde o aluno pode dedicar, com maior ênfase, a sua capacidade de originalidade através da relação de causa e efeito entre os argumentos. Eis o primeiro e o segundo parágrafos de desenvolvimento da redação em análise:

Quadro 2: Trechos 2 e 3, Aluno 1, Texto 1.

\begin{tabular}{l} 
Primeiramente, um grande fator que contribui para o analfabetismo funcional é a exclusão da escola, \\
que refere se aquelas contigências da população que se quer tiveram acesso a escola; apesar de ser mais \\
frequentes nas gerações anteriores que não viveram a expanção do ensino nas últimas décadas, também é \\
importante ressaltar sobre a problemática da localização da escola que está inserida nos grandes centros, \\
propiciando a evasão daqueles que habitam em lugares mais afastados, devido ao longo percurso de \\
deslocamento necessário até a escola (TRECHO 2). \\
\hline $\begin{array}{l}\text { Ademais, há uma produção do analfabetismo rudimentar mediado pela escola e está atrelada a baixa } \\
\text { qualidade de ensino, causada pela falta de verba para o investimento na educação de Jovens e adultos, } \\
\text { segundo o FUMDEB - Fundo de manutenção e desenvolvimento da educação básica, atualmente tem } \\
\text { cotação de investimento menor que 1\%, sendo o mais baixo fator de ponderação na educação, acaba } \\
\text { desestimulando os governantes a investirem. Contudo, segundo o economista britânico Sir Arthur Lewis, } \\
\text { a educação não será despesa, mas sim investimento que propiciaria retorno, diante do exposto, percebe-se } \\
\text { que o investimento na educação não é visto dessa forma. (TRECHO 3). }\end{array}$ \\
\hline
\end{tabular}

Dados da Oficina, 2019.

Percebemos, nos dois parágrafos de desenvolvimento, o comprometimento da produtividade dos argumentos em virtude da falta de coerência entre as ideias. Apesar da legitimação dos argumentos no trecho três e do desenvolvimento das problemáticas apontadas na tese, como se vê nos parágrafos analisados no Quadro 2, a falta de uma relação e de organização entre os argumentos, que sejam textualmente adequados ao sentido geral indicado no parágrafo de introdução, prejudica a efetiva defesa do ponto de vista do aluno.

Ao corrigirmos essa redação, pontuamos as competências II e III com a nota $160^{17}$, pois não houve a mobilização plena das habilidades necessárias para atingir a nota máxima nestas competências, afetando, assim, a elaboração de um projeto de texto ${ }^{18}$ ideal.

Assim como os excertos analisados do aluno 1, o segundo aluno também apresentou problemas concernentes às competências II e III nas primeiras produções textuais feitas em nossas aulas. A fim de exemplificar tais dificuldades, selecionamos o segundo parágrafo de desenvolvimento do tema similar ao texto analisado acima; vejamos o trecho:

17 Todas as correções das produções textuais dos alunos feitas ao longo da oficina de argumentação pautavam-se nos critérios utilizados pela grade específica de competências da redação do Enem e, por conta disso, optou-se pela utilização desse mesmo sistema de avaliação neste artigo. 18 Abaurre (2012, p. 11) define projeto de texto como "um esquema geral da estrutura de um texto, no qual se estabelecem os principais pontos pelos quais deve passar a argumentação a ser desenvolvida". 
Quadro 3: trecho 4, aluno 2, texto 1.

Ademais, o analfabetismo rudimentar é causado pela questão da desigualdade no Brasil, sendo ligada principalmente a questões sociais, pois, alguns habitantes deixam de frequentar as instituições de ensino para trabalhar. Segundo a ONU, a sociedade brasileira possui historicamente altos indices de trabalho infantil, devido a desiguldade social no país. No mesmo contexto, o trabalho demanda de uma atenção maior. Logo, alguns indivíduos acabam se tornando analfabetos funcionais por não possuirem tempo suficiente para estudar, tendo uma dificuldade maior para compreender tal temática abordada em sala de aula.

Dados da oficina, 2019.

O aluno apresenta os aspectos básicos de um parágrafo de desenvolvimento do tipo dissertativo-argumentativo, como o desenvolvimento de uma das problemáticas apontadas na tese e o uso de repertório sociocultural legitimado ao citar a Organização das Nações Unidas (ONU). Entretanto, não há o desenvolvimento produtivo de alguns dos argumentos ao longo do parágrafo, como nas passagens "o trabalho demanda de uma atenção maior" e "tendo uma dificuldade maior para compreender tal temática abordada em sala de aula".

Similarmente à primeira redação, o aluno atingiu a nota 160 nas competências II e III, o que aponta problemas na produtividade dos argumentos e algumas falhas no projeto textual.

A originalidade é uma das condições exigidas para o desenvolvimento do aspecto autoral na redação dissertativo-argumentativa do Enem. No entanto, o que percebemos na prática das aulas de produção textual no Brasil, principalmente no Ensino Médio e nos cursinhos, é o ensino de "fórmulas" textuais aos alunos. Sob o mesmo raciocínio, Bunzen (2006, p. 148) delineia esta prática de ensino enquanto pedagogia da exploração temática, ou seja, "propostas de produção de texto que solicitam aos alunos que escrevam uma redação sobre determinado tema, sem definir um objetivo específico, sem preocupação sociointerativa explícita".

Apesar da dificuldade de praticar outras alternativas de ensino, nós, enquanto residentes, procurávamos debater, juntamente com os alunos, as consequências negativas dessa forma de ensino para a formação da competência escrita em diferentes condições sociointerativas presentes em nosso cotidiano.

No decorrer da oficina, constatamos a evolução qualitativa de alguns discentes, principalmente os mais assíduos, nas competências II e III. Durante as aulas, debatíamos a influência das problemáticas sociais de cada tema para a persistência da desigualdade social histórica em nosso país. Assim, buscávamos fomentar a capacidade crítica dos alunos e não apenas a reprodutibilidade de informações para um único fim, a escrita de uma redação de vestibular ${ }^{19}$.

As passagens que escolhemos para analisar a melhora no desempenho das competências II e III foram retiradas do tema "Os desafios do ensino a distância no Brasil",

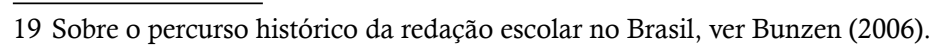


que foi discutido por nós em agosto de 2019. Selecionamos os primeiros parágrafos de desenvolvimento de ambos os alunos:

Quadro 4: trecho 5, aluno 1, texto 2.

Primeiramente, há o problema de exclusão digital, situação agravada pela falta de contato do indivíduo
com a internet este fato impossibilita o objetivo de democratização da Educação a Distância. Conforme
uma pesquisa realizada pelo Instituto Brasileiro de Geografia e Estatística (IBGE), 4 a cada 10 brasileiros
não possuem acesso à internet. Este dado expressa a inviabilidade da educação a distância ser empregada
em primeiro plano, sem a inclusão digital, e como única opção de ensino.

Dados da oficina, 2019.

Quadro 5: trecho 6, aluno 2, texto 2.

\begin{abstract}
Em primeiro lugar, o ensino a distância tornou se mais acessível ao público estudantil devido a sua flexibilização. Em conformidade com o site Veja, cerca de $65 \%$ das mensalidades são mais baratas com esse ensino, uma vez que possui diversas vantagens, como por exemplo, a economia por parte dos gastos, tanto com espaço, quanto pelo baixo custo com mensalidade. Entretanto, nota se que o fácil acesso a esse sistema torna o precário, pois a falta de disciplina dos alunos e a falta de tempo destinado aos estudantes, por consequência, acarreta um rendimento baixo desses estudantes.
\end{abstract}

Dados da oficina, 2019.

Ainda que haja a presença de alguns desvios da norma culta e problemas coesivos nos dois trechos, tais ocorrências não comprometem o desenvolvimento e nem a relação entre os argumentos em ambos os casos. Ao contrário dos outros trechos analisados, percebemos nos casos acima a presença de argumentos legitimados e produtivos, em virtude da condução de um fio argumentativo coerente entre as ideias.

Observamos que, além da mera exposição de dados estatísticos, os alunos conseguiram convencer o leitor acerca da pertinência e da produtividade dos seus argumentos devido à consistência e à organização destes, configurando autoria e, portanto, o alcance da nota máxima nas competências II e III.

Pelo fato de a nossa experiência na Residência Pedagógica ter ocorrido durante o último ano da licenciatura em Letras-Português, conseguimos colocar em prática com os alunos da oficina o nosso aprendizado ao longo do curso e a concepção de língua que concebemos como aquela que proporciona o aprendizado do uso da língua materna nos mais diversos contextos sociocomunicativos presentes ao longo da nossa vida e com diferentes sujeitos sociais, não apenas aquele preconizado no interior da instituição escolar.

Seguindo essa linha de raciocínio, Bakhtin/Volochínov (2014, p. 99) assevera que "(...) a palavra está sempre carregada de um conteúdo ou de um sentido ideológico ou vivencial" (grifos do autor). Por conta desse caráter social e ideológico da palavra, faz-se imprescindível uma prática pedagógica, por parte dos professores de língua materna e/ou estrangeira, que desperte a capacidade crítica do discente.

Com a finalidade de avaliar a progressão dos alunos nas competências que regem a redação dissertativo-argumentativa, aplicamos um simulado na antepenúltima aula da oficina, mais especificamente no mês de outubro. $\mathrm{O}$ tema proposto foi " $\mathrm{O}$ atual pano- 
rama da impunidade no Brasil". Escolhemos dois parágrafos de desenvolvimento dos alunos já mencionados nesta seção que reiteram a evolução destes nas competências II e III, vejamos:

Quadro 6: TRECHO 7, ALUNO 1, TEXTO 3.

Primeiramente, têm se políticas de segurança pública disfuncionais acarretadas pela fragilidade das leis. De acordo com uma pesquisa do Instituto Sou da Paz, a cada 10 homicídios apenas 2 geram uma denúncia com potencial para se tornar um processo que leve a uma condenação. Isto se dá pela ineficácia das leis que ao serem ambíguas, estão flexíveis à interpretação de quem a usa. Desta forma, as leis acabam por contribuir com a impunidade.

Dados da oficina, 2019.

Quadro 7: trecho 8, aluno 2, texto 3.

Além disso, o processo de julgamento sobre determinado crime torna se lento, uma vez que há a ineficiência das leis voltadas para a punição. Exemplo disso é o desastre ambiental ocorrido em Mariana, o que causou e causa até hoje diversos prejuízos ambientais, sociais e econômicas. Isso ocorre devido a falta de fiscalização, principalmente nas empresas de grande porte e leis rígidas a fim de punir esses setores. Todavia, essa ineficiência faz com que não haja a comprimento da pena, visto que o processo de julgamento chega a ser lento. Desse modo, torna se necessário que esse cenário seja revisto.

Dados da oficina, 2019.

Apesar de se tratar de um contexto diferente em relação aos já citados, pelo fato de esta produção ser fruto de uma aplicação simulada, a qual, por sua natureza, não permitiu a realização do debate do tema previamente, os alunos conseguiram demonstrar a função de autoria através da apresentação de argumentos legitimados, coerentes com a temática e interligados entre os períodos. Percebemos, mais uma vez, desvios da norma culta e problemas coesivos, principalmente no segundo trecho, no entanto esses problemas não comprometeram a produtividade e a apresentação de um projeto textual estratégico. Vale ressaltar, contudo, que certamente na competência I, que avalia a norma culta, esses textos seriam penalizados no que tange aos erros/desvios. Ademais, as qualidades apontadas se expandem para o restante das duas redações, o que resulta em uma avaliação de 200 pontos nas competências II e III.

Grosso modo, avaliamos o processo ensino-aprendizagem desenvolvido na Oficina de Argumentação como produtivo, com destaque para os seguintes aspectos:

a. O espaço da Oficina de Argumentação se converteu num "laboratório" didático-pedagógico bastante estratégico para a vivência de um graduando em Letras-Língua Portuguesa, haja vista esse cenário ser bastante comum no métier diário do professor de LP do Ensino Médio. Nesse sentido, foi possível envolver planejamento das aulas (através dos 30 encontros desenvolvidos ao longo dos 9 meses de atuação, sob orientação da Coordenação da RP e supervisão da professora Preceptora da escola-campo); ministração dos conteúdos, a partir da sensibilização dos alunos frente aos temas abordados nos comandos das propostas de produção, o que prevê a necessidade de contextualiza- 
ção com base nos conhecimentos de mundo que os alunos têm, conduzindo-os para a construção de conhecimentos enciclopédicos, a serem manifestos como background na escrita do texto; correção dos textos a partir de uma grade de avaliação específica, que envolveu a compreensão da sistemática "por trás" do Enem, em que pese não a descrição de uma fórmula pronta para os alunos, mas sim uma reflexão quanto ao papel comunicativo de autor de um texto. Para isso, buscou-se desenvolver uma percepção relativa às escolhas que os alunos podem fazer para promover em seu texto maior relevância organizacional;

b. Pode-se verificar o desenvolvimento dos alunos participantes da Oficina no que diz respeito ao eixo produção de texto, com ênfase para o tipo dissertativo-argumentativo. A partir dos trechos, viu-se que a cada etapa da oficina os alunos mais assíduos avançaram quanto à qualificação de seus textos, dentro do prisma avaliativo requerido pelo Enem. Esse processo de trabalho, inclusive, gerou frutos, já que alunos participantes da Oficina alcançaram resultados de aprovação no Enem 2019, conseguindo notas bastante altas (960, por exemplo) no exame;

c. Reflexão quanto ao desafio do ensino da produção de texto no contexto do Ensino Médio. Em que pese, uma forte prescrição em termos de unanimidade para o texto dissertativo-argumentativo, haja vista o interesse dos alunos pela aprovação no Enem, consequentemente, entrada em curso superior, houve ainda a dificuldade de se explorar as condições de reescrita, como sugerem os autores citados em nosso aporte teórico. A esse respeito, vale frisar, nosso planejamento previa ações de reescrita dos textos decorrentes de cada encontro de produção, contudo, houve pouca adesão por parte dos alunos, demonstrando como essa ação metodológica no ensino da produção de texto ainda requer reflexão por parte do professor, em termos do convencimento de sua funcionalidade e produtividade para os alunos;

d.Por fim, indicam-se resultados prático-institucionais. Em decorrência de uma vivência ampla, como requer o programa da Residência pedagógica, que prevê 18 meses de atuação, foi possível desenvolver uma Oficina por 9 meses seguidos, semanalmente, com o mesmo grupo de alunos. Esse aspecto é um valor prático muito relevante para os futuros professores de Língua Portuguesa em formação, que não encontra respaldo semelhante, por exemplo, nos tradicionais estágios supervisionados comuns às grades curriculares dos cursos de Letras. A imersão pela qual o residente passa no cotidiano escolar, experienciando, inclusive, outros espaços como reuniões de pais e mestres, planejamento anual da escola-campo, apenas para citar alguns exemplos, configuram avanço necessário à natureza das Licenciaturas. 


\section{CONSIDERAÇÕES FINAIS}

A participação na Residência Pedagógica nos permitiu imergir no contexto escolar ainda no período da graduação, o que contribuiu significativamente para o nosso aperfeiçoamento enquanto profissionais da educação. Percebemos, durante o nosso período no projeto, as dificuldades da profissão e a necessidade de uma constante atualização teórica e prática para o alcance de um ensino reflexivo da língua. Além disso, conseguimos efetivar a melhoria na capacidade de escrita dos alunos comprometidos com a oficina, mediante práticas pedagógicas que tentaram romper com o ensino de produção textual tecnicista, tão recorrente na história do ensino de língua portuguesa, pois acreditamos que "em qualquer instituição, até as mais inflexíveis e sedimentadas, há espaço para mudar, (...) pois os contextos não estão já dados; os participantes, de fato, criam contexto de ação" (KLEIMAN, 2006, p. 25).

Os resultados positivos nas notas das redações do Enem, dos alunos que participaram assiduamente da oficina, comprovam o impacto que a intervenção da Residência Pedagógica alcançou na formação escolar dos discentes do IFPB, tendo em vista o ingresso de muitos desses alunos em instituições de ensino superior. Isso mostra a relevância social de programas educacionais como a Residência Pedagógica para a promoção de uma disputa mais igualitária, entre alunos de escolas públicas e particulares, nas provas de vestibular no Brasil.

É sabido que a implementação do Exame Nacional do Ensino Médio (Enem) como principal exame para a entrada no ensino superior público no Brasil modificou o conteúdo das aulas de produção textual do Ensino Médio, tendo em vista que o tipo textual dissertativo-argumentativo é o único cobrado na prova. Tal aspecto impactou significativamente a atuação do docente de Língua Portuguesa, uma vez que há a necessidade, no ensino médio, de uma prática pedagógica direcionada quase que exclusivamente para um único tipo textual. No entanto, um ensino de produção textual que objetiva preparar o cidadão para lidar com diferentes contextos comunicacionais precisa abarcar diferentes tipologias, como apontam os PCN+ (2002). Sendo este um desafio atual para os professores de língua portuguesa do ensino médio brasileiro. Desse modo, a relação entre teoria e prática, estimulada pela Residência Pedagógica, propicia uma experiência prévia ao licenciando o que, consequentemente, contribui para a formação de um profissional melhor capacitado para enfrentar os desafios da prática docente e mais apto para efetivar a consolidação de novas perspectivas metodológicas de ensino.

Em suma, o contexto de aprendizagem promovido pela vivência na Residência Pedagógica, núcleo de Letras Português da Universidade Federal da Paraíba (UFPB), Campus I, oportunizou impactos muito significativos para a formação docente, haja vista o lócus da escola-campo, as ações desempenhadas, as trocas de saberes desenvolvidas na oficina, na relação com os alunos, com a professora preceptora, com os orientadores pedagógicos conferirem ao residente, professor(a) em formação, um olhar prático e de protagonismo docente, imperando, nesse processo um dos aspectos fundamentais a qual- 
quer licenciatura: o aprender a ensinar. Logo, a RP forneceu condições (a)(os) futuro(a) (s) professor(a)(s) para o saber fazer/manejar as técnicas e teorias difundidas na graduação a partir da relação direta com a sala de aula e o chão da escola.

\section{REFERÊNCIAS}

ABAURRE, Maria Luiza M.; ABAURRE, Maria Bernadete. Um olhar objetivo para produções escritas: analisar, avaliar, comentar. 1. Ed. São Paulo: Moderna, 2012.

BAKHTIN/VOLOCHÍNOV. Marxismo e filosofia da linguagem: problemas fundamentais do método sociológico da linguagem. Trad. Michel Lahud e Yara Frateschi Vieira. 16ª ed. São Paulo: Hucitec, 2014.

BRASIL. A redação do ENEM: cartilha do participante. MEC, INEP, DAEB, 2020. Disponível em: <https:// download.inep.gov.br/publicacoes/institucionais/avaliacoes_e_exames_da_educacao_basica/a_redacao_do_ enem_2020_-_cartilha_do_participante.pdf>, acesso em 15 mar. 2021.

. Enem Redações 2019: Material de leitura - Módulo 5 Competência III. INEP, 2019.

. Matriz de Referência Enem. Disponível em: https://download.inep.gov.br/download/enem/matriz referencia.pdf, acesso em 13 de março de 2021.

. Base Nacional Comum Curricular: Educação Infantil e Ensino Fundamental. Brasília: MEC/Secretaria de Educação Básica, 2017. Disponível em: <http://basenacionalcomum.mec.gov.br/images/BNCC EI EF 110518 versaofinal site.pdf $>$, acesso em 26 fev. 2020.

. PCN+ Ensino médio: orientações educacionais complementares aos Parâmetros Curriculares NacionaisCiências da Natureza, Matemática e suas Tecnologias. 2002.

. Proposta de diretrizes para a formação inicial de professores da educação básica em cursos de nível superior. Brasília: MEC/SEF, 2000.

BUNZEN, Clécio. Da era da composição à era dos gêneros: o ensino de produção de texto no ensino médio. In: Português no ensino médio e formação do professor / Clécio Bunzen, Márcia Mendonça (organização). - São Paulo : Parábola Editorial, 2006.

CUNHA, D. A. C. (2004). Uma análise de concepções e conceitos: linguagem, língua, sentido, significação, gênero e texto. In: SOUSA, M. E. V.; VILAR, S. F. P. (orgs.) (2004). Parâmetros curriculares em questão: ensino médio. João Pessoa: Editora da UFPB, pp. 27-47.

FOUCAULT, Michel. O que é um autor? In: . Ditos \& Escritos. Rio de Janeiro: Forense Universitária, 2009. v. 3.

GERALDI, João Wanderley. O texto na sala de aula. - São Paulo: Editora Ática, 2006.

KLEIMAN, Ângela. Leitura e prática social no desenvolvimento de competências do ensino médio. In: Português no ensino médio e formação do professor / Clécio Bunzen, Márcia Mendonça (organização). - São Paulo : Parábola Editorial, 2006.

MARCUSCHI, Luiz Antônio. Produção textual, análise de gêneros e compreensão. Parábola Ed., 2008.

MATA, Anderson. Originalidade e consciência da escrita: indícios de autoria na argumentação em textos escolares. In: Textos dissertativo-argumentativos : subsídios para qualificação de avaliadores / Lucília Helena do Carmo Garcez, Vilma Reche Corrêa, organizadoras. - Brasília : Instituto Nacional de Estudos e Pesquisas Educacionais Anísio Teixeira, 2017.

MOITA LOPES, L. P. da. Linguística aplicada e vida contemporânea problematização dos construtos que têm orientado a pesquisa. In: . (Org.). Por uma linguística aplicada indisciplinar. São Paulo: Parábola, 2006, pp. 85-107.

ROJO, Roxane; CORDEIRO, Glaís Sales. Gêneros orais e escritos na escola. Campinas: Mercado de Letras, 2004. TRAVAGLIA, Luiz Carlos. Gramática e interação: uma proposta para o ensino de gramática no $1 .^{\circ} \mathrm{e} 2 .^{\circ}$ graus. São Paulo: Cortez, 2002.

TRINDADE, Mônica. Sobre o ensino de gramática: uso e reflexão nas aulas de língua portuguesa. In: Linguística aplicada à língua portuguesa no ensino médio: reflexões teórico-metodológicas. 2.ed. / Pedro Farias Francelino, organizador. -- João Pessoa: Editora da UFPB, 2014. 